\title{
Inserção da Sustentabilidade no Curso de Administração: Ensaio teórico
}

\author{
Insertion of Sustainability in the Administration Course: Theoretical essay \\ Inserción de Sostenibilidad en el Curso de Administración: Ensayo teórico
}

Recebido: 12/07/2021 | Revisado: 16/07/2021 | Aceito: 21/07/2021 | Publicado: 29/07/2021

\author{
Simone Coelho Amestoy \\ ORCID: https://orcid.org/0000-0001-8310-2157 \\ Universidade Federal do Vale do São Francisco, Brasil \\ E-mail: simoneamestoy@hotmail.com \\ Paulo Roberto Ramos \\ ORCID: https://orcid.org/0000-0003-3684-0960 \\ Universidade Federal do Vale do São Francisco, Brasil \\ E-mail: paulo.ramos@univasf.edu.br
}

\begin{abstract}
Resumo
Objetivo: fomentar reflexões sobre a inserção de temas ambientais e sustentáveis no Curso de Administração. Método: consiste em um ensaio teórico desenvolvido a partir da análise da produção científica sobre a temática. Resultados: nem todos os Cursos de Administração possuem um componente curricular específico que abarca a educação ambiental. Alguns buscam propor atividades que envolvem o assunto e possibilitam a interação com outros cursos, transpondo a disciplinaridade em um caminhar para o alcance da transdisciplinariedade preconizada nas Diretrizes Curriculares Nacionais para Educação Ambiental. Considerações finais: no curso de Administração o assunto costuma estar presente, mas ainda são necessários maiores investimentos e articulações para que transcenda a apresentação em disciplinas isoladas e passe a ocorrer de forma transdisciplinar, aproveitando os diversos espaços de formação, como grupos e projetos de pesquisa e projetos de extensão. Outra possibilidade é a abordagem transversal da educação ambiental, para que possa ser discutida com os estudantes desde os semestres iniciais.
\end{abstract}

Palavras-chave: Educação ambiental; Sustentabilidade; Administração.

\begin{abstract}
Objective: foster reflections on the inclusion of environmental and sustainable themes in the Administration Course. Method: it consists of a theoretical essay developed from an analysis of the scientific production of the theme. Results: not all Administration Courses have a specific curricular component that encompasses environmental education. Some seek to propose activities that involve the subject and make it possible to interact with other courses, transposing disciplinarity in a journey towards achieving the transdisciplinarity advocated in the National Curriculum Guidelines for Environmental Education. Final considerations: in the Administration Course the subject is usually present, but greater investments and articulations are still needed to transcend the presentation in isolated disciplines and start to occur in a transdisciplinarity way, taking advantage of the various training spaces, such as research groups and projects and extension projects. Another possibility is the transversal approach to environmental education, so that it can be discussed with students from the initial semesters.
\end{abstract}

Keywords: Environmental education; Sustainability; Management.

\section{Resumen}

Objetivo: promover reflexiones sobre la inclusión de temas ambientales y sostenibles en el Curso de Administración. Método: consiste en un ensayo teórico desarrollado a partir de un análisis de la producción científica del tema. Resultados: no todos los cursos de administración tienen un componente curricular específico que abarque la educación ambiental. Algunas buscan proponer actividades que involucren la asignatura y permitan interactuar con otros cursos, transponiendo la disciplinariedad en un camino hacia el logro de la transdisciplinariedad recomendada en los Lineamientos Curriculares Nacionales de Educación Ambiental. Consideraciones finales: en el curso de Administración la asignatura suele estar presente, pero se necesitan mayores inversiones y articulaciones para trascender la presentación en disciplinas aisladas y comenzar a ocurrir de manera transdisciplinar, aprovechando los diversos espacios de formación, como grupos y proyectos de investigación y proyectos de extensión. Otra posibilidad es el enfoque transversal de la educación ambiental, para que se pueda discutir con los estudiantes desde los primeros semestres.

Palabras clave: Educación ambiental; Sustentabilidad; Gestión. 


\section{Introdução}

A Lei no 9.795, de 27 de abril de 1999, que trata da educação ambiental no âmbito nacional, em seus artigos iniciais, estabelece os princípios e normas para sua aplicação e desenvolvimento em todos os níveis e modalidades do processo educativo formal e informal. Nesse sentido, a legislação se utilizando de princípios e valores individuais e coletivos como pressupostos essenciais para a harmonia da vida dos cidadãos em relação ao uso sustentável dos recursos naturais (Brasil, 1999).

O meio ambiente, por se tratar de um conjunto de condições que rege o dia a dia da população, é matéria de interesse nacional, motivo pelo qual todos os envolvidos (públicos e privados) foram relacionados no presente dispositivo legal. Ressalta-se que a lei em estudo, foi promulgada com a finalidade de regulamentar aquilo que estava previsto no texto constitucional de 1988.

Este marco legal trata a educação ambiental como finalidade do entendimento sistemático que envolve o estudo no campo ecológico, psicológico, legal, político, social, econômico, científico, cultural e ético, com o escopo de oportunizar que todas as pessoas possam ter acesso às informações relacionadas às temáticas ambientais, com isso estimulando e cristalizando o censo crítico ao fomentar a participação da coletividade nos debates sobre preservação do equilíbrio do meio ambiente (BRASIL, 1999).Cabe salientar que existem duas formas de se proceder a educação ambiental, conforme estabelecido em lei, sendo por meio formal mediante estabelecimento de práticas de ensino convencionais, e informal que costuma ocorrer pela sensibilização do indivíduo por diversos meios informacionais.

No contexto do ensino superior, cabe destacar o Programa Nacional de Educação Ambiental (ProNEA) criado com o objetivo de promover a educação ambiental em todos os níveis, desde a educação básica até o ensino superior, buscando a conscientização da população para a defesa e garantia de um meio ambiente equilibrado e preservado. O Programa supracitado defende o ensino da Educação Ambiental de modo transversal nos componentes curriculares, além de estar presente em documentos legais, desde o Projeto Pedagógico dos Cursos aos planos de disciplinas, bem como sua implementação em uma prática pedagógica que promova a educação ambiental contextualizada com a realidade dos estudantes (Brasil, 2005).

No ano de 2012 foram criadas as Diretrizes Curriculares Nacionais para a Educação Ambiental, as quais estabelecem que as instituições de Educação Superior devem promover sua gestão e suas ações de ensino, pesquisa e extensão orientadas pelos princípios e objetivos da Educação Ambiental. No que concerne à organização curricular, as Diretrizes Curriculares dispõem acerca da importância da inserção dos conhecimentos concernentes à Educação Ambiental nos currículos da Educação Básica e da Educação Superior e deve ocorrer por meio da transversalidade, mediante temas relacionados com o meio ambiente e a sustentabilidade socioambiental assim como conteúdo dos componentes já constantes do currículo (Brasil, 2012).

Mesmo com a aquisição de certos avanços com a criação da Política Nacional de Educação Ambiental e das Diretrizes Curriculares Nacionais para a Educação Ambiental, Lopes e Morais (2018), sinalizam que as pessoas valorizam muito a educação ambiental informal, sendo essa imprescindível, porém corre o risco de ficar limitada à criação de cartilhas e cartazes. Frente ao exposto, torna-se essencial preparar os estudantes, desde a educação formal, para terem um olhar voltado para o meio ambiente. Além disso, há carência de uma visão ambiental histórica em todas as disciplinas do currículo escolar. Também evidencia-se a falta de investimentos na formação de professores com uma visão multidisciplinar, valorizando também as questões éticas.

Diante da importância do assunto em pauta, investigações foram realizadas abrangendo os diferentes níveis de formação. Destaca-se pesquisa realizada com o intuito de analisar a percepção dos gestores de uma rede de ensino básico e superior privado, quanto a prática da Educação Ambiental e da Agenda 2030, na perspectiva da Teoria Institucional. Os achados indicaram que a Rede Sinodal de Ensino ainda possui fragilidades frente à institucionalização das demandas no ensino 
relacionadas à Política Nacional de Educação Ambiental e da Agenda 2030 (CAPPONI et.al., 2021), o que desperta para a necessidade de um olhar mais acurado no que concerne à inserção da educação ambiental na formação, envolvendo os estudantes do ensino básico até o ensino superior.

Corroborando com este resultado, pesquisa com o objetivo de analisar o papel da gestão no fazer ambiental nas instituições de ensino superior, a partir do estudo de caso do Instituto Federal do Tocantins-Campus Porto Nacional, sinaliza para a necessidade de integração dos cursos superiores aos projetos envolvidos e desenvolvidos pelo campus. Identificou-se ainda, que a educação ambiental é pouco ofertada nos cursos superiores noturnos, devido a maioria dos estudantes trabalharem durante o dia e morarem em cidades circunvizinhas. Anseia-se pela criação de espaços estruturados de educação ambiental nas Instituições de Ensino Superior, fomentada por discussões dialógicas entre a comunidade acadêmica e outros atores sociais, em uma perspectiva de educação permanente. O estudo também indica a importância do papel dos docentes, os quais devem estimular à visão complexa da questão ambiental, a partir das interações e relações dinâmicas entre ambiente, questões políticas, cultura e sociedade, que influenciam na relação humana com o ambiente sustentável (Carvalho \& Bispo, 2019).

Quanto ao ensino na Pós-Graduação, Profice (2016) analisou os resultados de investigações em Educação Ambiental do Curso de Mestrado em Desenvolvimento Regional e Meio Ambiente (MDRMA) da Universidade Estadual de Santa Cruz (UESC) entre 2001 e 2014. A pesquisadora verificou que apesar de compreenderem o tema ambiental relevante e a Educação Ambiental pertinente, os professores ainda não se consideram preparados para conduzi-la. Neste período, foram defendidas 308 dissertações, destas somente 22 abordaram a Educação Ambiental e apenas cinco tiveram seus resultados publicados em periódicos científicos, o que sinaliza para limitação no impacto científico das pesquisas oriundas do Programa. Na grade curricular, existia uma disciplina optativa sobre a temática, a qual havia sido ministrada dez vezes, por mais de quatro professores diferentes, no interstício de 17 anos.

Os resultados acima subsidiam a importância da abordagem da educação ambiental e de temas que permeiam a temática, como é o caso da sustentabilidade, envolvendo tanto os professores como os estudantes em atividades de ensino, projetos e propostas metodológicas que auxiliem na sensibilização quanto ao assunto.

A sustentabilidade caracteriza-se como um processo que deve ser planejado em longo prazo, o que requer um equilíbrio entre o atual modelo de desenvolvimento, considerado capitalista-industrial, uma vez que este é necessário, porém se faz imprescindível outra perspectiva de sustentabilidade que considere o pleno desenvolvimento, agregando as diferentes formas de vida na Terra, além da integração das dimensões política, social, econômica e ambiental que somente terá a integralidade do desenvolvimento sustentável, mediante à educação ambiental (Roos \& Becker, 2012). Desta forma, trata-se de uma temática transversal e interdisciplinar, que deve ser abordada também nas instituições de ensino superior.

Voltando-se o olhar para o campo da Administração, torna-se imprescindível destacar a partir das novas exigências de profissionalização requeridas pelo mercado de trabalho, que cabe aos cursos de Administração a adoção de uma nova proposta de formação profissional e de ensino-aprendizagem, com vistas a consolidar um perfil generalista e polivalente. Esse arranjo parece ser uma estratégia plausível para o desenvolvimento de competências e habilidades atualmente necessárias ao administrador, levando-se em consideração as transformações organizacionais e ambientais (Malta \& Calloni, 2018).

Ante o exposto, o estudo em questão tem como finalidade à inserção da sustentabilidade no Curso de Administração, tendo em vista a importância do engajamento dos estudantes em projetos que fomentem a temática e após, enquanto gestores inseridos no mercado de trabalho, os quais deverão possuir competências, bem como conhecimentos e habilidades que subsidiem sua prática gerencial.

Destaca-se a necessidade de criação de estratégias que potencializem a abordagem da sustentabilidade de modo transversal, ou seja, ao logo do Curso de Administração e que proporcionem uma aprendizagem significativa para os 
estudantes, podendo estes tornarem-se agentes ativos de transformação, em busca de práticas que consolidem a educação ambiental, além dos muros da Universidade.

O estudo tem por objetivo fomentar reflexões sobre a inserção de temas ambientais e sustentáveis no Curso de Administração.

\section{Metodologia}

Consiste em um ensaio teórico desenvolvido a partir da revisão de autores que abordam a problemática da relação entre educação ambiental e sustentabilidade aplicadas ao Curso de Administração.

A partir deste ensaio teórico buscou-se desenvolver exposição lógica e reflexiva associada à argumentação e interpretação do pesquisador. Cabe mencionar que as reflexões tecidas são embasadas na análise crítica da literatura produzida sobre a temática em pauta, juntamente com a argumentação e interpretação realizada pelos autores (Severino, 2007).

\section{Resultados e Discussão}

Com base nos resultados da análise dos estudos produzidos sobre a temática, definiu-se duas categorias: "Concepções teóricas atribuídas à sustentabilidade" e "Inserção da sustentabilidade na Administração", as quais serão apresentadas na sequência.

\section{Concepções teóricas atribuídas à sustentabilidade}

As questões ambientais e a preocupação com a sustentabilidade vêm ganhando, cada vez mais espaço e a Universidade Pública tem papel fundamental na formação de profissionais comprometidos com as preocupações ambientais em suas áreas. No caso do Curso de Administração, na formação de gestores que irão se deparar com desafios e decisões que tangenciam essas temáticas.

Os estudos das últimas três décadas vêm apontando que empresas que possuem em seus objetivos estratégicos preocupações com o meio ambiente e a sustentabilidade, e implementam ações em prol do meio ambiente e da sociedade, tendem a ganhar maior visibilidade e valorização de seus clientes e consumidores. O benefício agregado é multifatorial, ou seja, para o meio ambiente, consumidor, organizações e sociedade como um todo.

Destaca-se que os termos sustentável, sustentabilidade e desenvolvimento sustentável, ainda não possuem um consenso, mesmo sendo muito difundidos na literatura (Feil \& Schreiber, 2017). Nesta direção, torna-se imprescindível resgatar os conceitos teóricos que embasam o conceito de sustentabilidade, haja vista que existem diversas compreensões a seu respeito.

O conceito da sustentabilidade precisa ser compreendido sob a perspectiva da abordagem transdisciplinar, tendo em vista que se reconhece que as ciências disciplinares não conseguiram trabalhar de forma construtiva com os muitos conceitos ambientais, inclusive o da sustentabilidade (Mikhailova, 2004). De acordo com este entendimento, é necessário um olhar sob vários prismas, de diversos campos do conhecimento, para que seja possível abarcar melhor a sustentabilidade em sua complexidade.

Jacobi (1999) complementa que uma política de desenvolvimento na direção de uma sociedade sustentável não pode desconsiderar as dimensões culturais, nem tampouco as relações de poder existentes e o reconhecimento das limitações ecológicas, sob pena de apenas manter um padrão predatório de desenvolvimento.

Assim, infere-se que o agente implementador da sustentabilidade, como meio de vida cotidiana, seja público ou privado, deve se nortear pelo distanciamento das condutas pragmáticas já utilizadas, ao passo que somente com a ruptura dos padrões é que se torna possível mitigar a devastação deixada pela evolução pautada em uma cultura exploratória. 
Também é importante resgatar os conceitos de sustentabilidade e o desenvolvimento sustentável, os quais são termos entrelaçados e envolvidos com propósitos semelhantes, uma vez que a sustentabilidade é o objetivo do desenvolvimento sustentável (Carvalho \& Bispo, 2019). Nessa esteira de pensamento, ambos conceitos se diferem apenas pelo fato de que a sustentabilidade é direcionada para conscientizar as pessoas de que o consumismo deve ser deixado de lado, com vistas a privilegiar aqueles que adotam como forma de vida uma política de consumo mínimo, excluindo ou reduzindo ao máximo o descarte de materiais não renováveis, assim fomentando a reciclagem e consequentemente, a preservação do meio ambiente; enquanto que o desenvolvimento pensado de forma sustentável se trata de uma teoria que visa mudar atitudes individuais que favorecerão o todo.

A sustentabilidade consiste na capacidade de se sustentar, isto é, de se manter. Considera-se uma atividade sustentável, quando ela pode ser preservada para sempre. Por exemplo, a exploração de um recurso natural realizada de maneira sustentável tem longa durabilidade, pois se renova e tende ao infinito. Desta forma, uma sociedade sustentável caracteriza-se como aquela que preserva o meio ambiente, não colocando-o em risco e, consequentemente, nem a si própria (Mikhailova, 2004).

Para tanto, torna-se imprescindível que a sociedade seja sensibilizada para a importância de preservar o meio ambiente e de pensar em estratégias que fomentem a sustentabilidade. A educação ambiental promovida desde a formação básica ao ensino superior tem potencial para transformar a realidade e criar novas possibilidades de viver melhor, em coletividade e preservando o ecossistema.

Carvalho e Bispo (2019) enfatizam que a sustentabilidade abrange perspectivas que extrapolam a concepção ecológica e ambiental, sendo composta também por outras dimensões, tais como: econômica, cultural, política e histórica. No que tange à sustentabilidade, sob o entendimento ambiental e ecológico, a mesma representa a sustentação dos ecossistemas e a sua capacidade de absorção e recomposição feita pela ação antrópica, assim como as condições que se fazem essenciais para a manutenção da vida sem gerar prejuízos as gerações futuras. Quanto à dimensão social, a sustentabilidade é permeada pelos direitos humanos e pela justiça social.

Isto posto, Feil e Schreiber (2017) complementam que a sustentabilidade expressa a preocupação com a qualidade de um sistema que valoriza a articulação indissociável entre o meio ambiente e o ser humano, bem como avalia suas propriedades e características, envolvendo aspectos ambientais, sociais e econômicos.

Os autores ainda afirmam que a sustentabilidade relaciona-se com a mensuração do nível da qualidade deste sistema com intuito de avaliar o seu grau de distanciamento em relação ao sustentável. Tal avaliação é realizada a partir de indicadores e índices de sustentabilidade, os quais podem identificar os aspectos que são responsáveis por não alcançar o nível sustentável desejado e os que devem ser reposicionados ou melhorados, podendo ser de cunho ambiental, social ou econômico (Feil \& Schreiber, 2017).

Já o desenvolvimento sustentável é um conceito que nasceu marcado pela tentativa de harmonizar o desenvolvimento econômico, a prudência ambiental e a justiça social. Inspirando as políticas para melhoria da qualidade da vida dos seres humanos, ao passo que respeita a capacidade de produção dos ecossistemas (Mikhailova, 2004). Para Feil e Schreiber (2017) trata-se de estratégias para aproximar o nível de sustentabilidade ao sistema ambiental humano sustentável.

A perspectiva de desenvolvimento sustentável emerge como uma força desafiadora e proposta integradora, com vistas a qualificar a necessidade de promover outras formas de desenvolvimento e tem por escopo atuar em prol do equilíbrio em relação às capacidades e às fragilidades existentes. Neste sentido, o desenvolvimento sustentável não se restringe a um problema limitado de adequações ecológicas de um processo social, mas sim, caracteriza-se como uma estratégia ou para a sociedade, a qual deverá considerar tanto sua viabilidade econômica quanto a ecológica (Jacobi, 1999).

Dessa forma, nota-se que a implementação de uma mudança na maneira em que é abordado o consumo e a exploração 
dos recursos por uma população vai mais além do que uma mudança local, uma vez que para se materializar a conscientização das pessoas é necessária a elaboração de uma política pública que seja permeável entre a manutenção e exploração racional dos recursos naturais, uma vez que há uma linha tênue entre ambas que dependendo da maneira que é abordada pode ser prejudicial tanto para a população quanto para à natureza.

De acordo com Feil e Schreiber (2017) o desenvolvimento sustentável requer instrumentos para aproximar o sistema ambiental humano ao nível de sustentabilidade, com o intuito de preservar a vida de forma harmoniosa e que perdure por um longo do tempo, o que impulsiona a ruptura de paradigmas por meio de mudanças no entendimento e posicionamento cultural da sociedade.

Considerando os acontecimentos históricos que marcaram a sustentabilidade, convém retomar Conferência de Estocolmo em 1972, considerada o marco inicial para o desenvolvimento sustentável, em que emergiu a necessidade de valorizar e reaprender a conviver com o planeta. Todavia, o desenvolvimento sustentável só passou a ser pauta de políticas ambientais, a partir da Conferência das Nações Unidas sobre Meio Ambiente e Desenvolvimento (Rio-92) (Mikhailova, 2004).

Em 2002, um conceito mais completo de desenvolvimento sustentável foi defendido na Cúpula Mundial em 2002, envolvia a definição mais concreta do objetivo de desenvolvimento atual, permeado pela a melhoria da qualidade de vida de todos os habitantes, ao passo que diferencia o fator limitante do desenvolvimento e pode gerar efeitos danosos as futuras gerações (Mikhailova, 2004).

A complexidade dos desafios experenciados pela sociedade exigem ações coletivas para a redefinir relações produtivas, cultural e social, para que se possa construir uma vivência mais sustentável e assertiva (Carvalho \& Bispo, 2019). Neste interim, torna-se fundamental a criação de oportunidades e novas possibilidades para inserir a problemática ambiental no universo da gestão local, e especialmente relacionada às políticas sociais. Destaca-se ainda que as ações dos seres humanos sobre o meio ambiente tem gerado impactos complexos, tanto quantitativos quanto qualitativos (Jacobi, 1999). Tal afirmação se faz ainda muito presente no cenário atual, e investimentos em estratégias que possam viabilizar a sustentabilidade e o desenvolvimento sustentável implicam em políticas públicas, bem como a participação da sociedade a partir do engajamento nas discussões e em ações efetivas.

No ano de 2015, foi a criação da Agenda 2030, outro acontecimento marcante relacionado à temática em pauta, constituída por 17 Objetivos de Desenvolvimento Sustentável, entre os quais se preocupam com: erradicar a pobreza; erradicar a fome; saúde e qualidade; educação de qualidade; igualdade de gênero; água potável e saneamento; energias renováveis e acessíveis; trabalho digno e crescimento econômico; indústria, inovação e infraestruturas; reduzir as desigualdades; cidades e comunidades sustentáveis; produção e consumo sustentáveis; ação climática; proteger a vida marinha; proteger a vida terrestre; paz, justiça e instituições eficazes e parcerias para implementação dos objetivos (UNRIC, 2015).

O caminho é desafiador, mas não há como voltar atrás e retroceder em termos de aprendizagem e experiência. É vital para a sociedade atual, assim como para as futuras gerações, que sejam pensadas ferramentas que possibilitem a projeção de ambientes sustentáveis e todas as áreas e espaços da vida humana.

\section{Inserção da sustentabilidade no Curso de Administração}

A educação ambiental vem ganhando visibilidade e adquire uma responsabilidade de transformação. Neste sentido, é fundamental investimentos na educação e em informação, tendo em vista a importância de sensibilizar as pessoas quanto aos problemas ambientais que afligem o planeta, para que possam colaborar com a preservação ambiental, mediante a construção de alternativas mais sustentáveis (Carvalho \& Bispo, 2019). Vale ressaltar que a Educação Ambiental é construída por meio responsabilidade cidadã e da reciprocidade das relações dos seres humanos entre si e com a natureza (Brasil, 2012)

Quanto ao ensino da educação ambiental, convém retomar que as alterações na Base Nacional Comum Curricular 
causaram repercussões e mudanças no ensino e na prática de educação ambiental nos cursos superiores. Estas transformações, ainda não estão claras nas normativas e diretrizes do sistema educacional brasileiro. Até o momento, o que se tem conhecimento é que estas modificações impulsionaram reflexões dos gestores e professores acerca do ensino, não comente sobre a importância da utilizar métodos mais adequados, mas também a respeito do conjunto de valores que formam os cidadãos (Carvalho \& Bispo, 2019).

A educação ambiental nas escolas, institutos e universidades precisa estar atrelada com as comunidades e movimentos sociais que se dedicam às questões ambientais. Nestes arranjos, compte às instituições de ensino superior assumir a frente das pesquisas e produção do conhecimento, promovendo a reflexão crítica sobre os problemas ambientais e as formas de enfrentamento que devem estar atreladas às políticas públicas e socioeconômicas (PROFICE, 2016).

Destarte, torna-se imperioso ampliar as discussões que permeiam a educação ambiental desde a educação básica e fundamental, passando pela formação técnica e ensino superior. É uma responsabilidade coletiva, por este motivo, quanto mais informação e espaços promotores de debates sobre o assunto, maiores serão as possibilidades de transformações da realidade e, por consequência, preservação do meio ambiente e construção de alternativas mais sustentáveis.

Capponi et.al.(2021) suscitam reflexões acerca da necessidade de instrumentalizar os professores, ao passo que estes serão os agentes promotores de ações fundamentais aos cuidados e preservação do meio ambiente, o que implica em um impacto coletivo às mudanças que se iniciam em sala de aula.

Pensando na formação, estudo realizado no Instituto Federal na Região Centro Oeste, evidenciou que a abordagem da educação ambiental possui lacunas e não é efetivamente trabalhada de forma interdisciplinar conforme orienta as diretrizes educacionais. Isto posto, convém mencionar que existem parcerias realizadas entre professores para desenvolver projetos de extensão, mas com enfoque disciplinar, dependendo do interesse e propostas dos envolvidos. Outro ponto a ser destacado é que os docentes desenvolvem suas ementas sem realizar reuniões e discussões coletivas, apoio pedagógico e acompanhamento de desempenho individual e conjunto (Carvalho \& Bispo, 2019). Esta fragmentação no ensino pode estar interferindo de modo prejudicial no processo de ensino-aprendizagem e no alcance dos objetivos de ensino e por contrapartida, afetará no modo como os estudantes compreendem a educação ambiental.

O desenvolvimento sustentável e ações de gestão ambiental tomaram uma enorme proporção, haja vista sua relevância e em virtude disso, galgou visibilidade nas instituições de ensino superior (Tauchen \& Brandli, 2006). Nesta esteira do pensamento, pode-se dizer que a educação ambiental e a sustentabilidade foram sendo incorporadas paulatinamente nos currículos dos cursos de graduação, buscando envolver estudantes e professores de diversas áreas do conhecimento.

No Curso de Administração essa nova perspectiva também tem estado presente. Na medida em que no momento atual, o administrador irá se deparar continuamente com questões ambientais, e suas repercussões para a sociedade e para o meio ambiente como um todo.

A respeito do ensino na Administração, um dos principais desafios da contemporaneidade é formar administradores preocupados e engajados com a questão ambiental e atuantes nas organizações (Malta \& Calloni, 2018). Complementa-se que a questão ambiental, no mundo empresarial, adquiri importantes esforços dos administradores, o que exige um novo perfil do profissional capaz de considerar e organizar uma estrutura administrativa que conduza os processos e todos os setores comprometidos com a responsabilidade social e ambiental (Teixeira \& Teixeira, 2006).

O administrador consiste no profissional que atua diretamente nas questões do cotidiano das organizações, e em sua maioria, desempenha papel fundamental no processo de tomada de decisão. Diante disso, torna-se vital a criação de espaço para sejam discutidos e analisados todos os riscos e impactos ambientais sobre o bem estar humano e ecossistemas. Em que pese ser uma tarefa desafiadora, é necessário investir na mudança de pensamento, postura e valores, de modo que estes profissionais possam colaborar efetivamente para o gerenciamento de questões socioambientais de forma mais assertiva e 
resolutiva (Malta \& Calloni, 2018).

Sugere-se com base em Teixeira e Teixeira (2006), que os cursos de graduação em Administração considerem seu currículo, abrangendo em seu projeto pedagógico e no processo ensino-aprendizagem, novas possibilidades de aprendizado, ou seja, disciplinas na formação profissional do administrador, entre elas a educação ambiental, a fim de acompanhar as transformações e as necessidades do mercado diante do processo de globalização.

Frente ao exposto, destaca-se estudo que objetivou analisar a percepção de discentes do curso de Administração da Universidade Federal do Rio Grande do Norte (UFRN) sobre o ensino da disciplina Gestão Ambiental. Os resultados indicam que 55\% dos alunos declararam que a disciplina possui um nível alto de relevância para o curso de Administração e 32\% consideraram nível médio de importância. Os participantes também revelaram que há pouca interdisciplinaridade do tema no Curso, porém existe uma considerável parcela dos estudantes já atuando em prol do meio ambiente fora do contexto acadêmico. Além disso, os estudantes concordam que a disciplina de Gestão Ambiental é significativa para o curso de Administração (Teixeira et.al., 2018).

Pesquisa realizada por Oliveira, Oliveira e Costa (2010) objetivou avaliar a importância da Gestão Ambiental na perspectiva de professores de Instituições de Ensino Superior em Administração localizadas na cidade de Fortaleza. Os participantes entendem a gestão ambiental como essencial para os cursos de Administração e, sinalizam que a necessidade moderada desta área nos cursos. Mesmo atribuindo grande relevância, o nível de intenções de envolvimento dos professores com a área foi baixo.

Outra investigação buscou desvelar como o ensino da sustentabilidade nas Instituições de Ensino Superior (IES) do Estado do Paraná é refletido no resultado do ENADE. Para seu desenvolvimento, as pesquisadoras analisaram as notas de todas das questões do ENADE do ano de 2012, de um total de 141 IES. As questões eram relacionadas a área da administração, com um enfoque na sustentabilidade. Os resultados indicam que a temática sustentabilidade ainda não é incipiente na formação dos administradores, evidenciada por certa fragilidade do entendimento dos estudantes diante da relação entre administração e sustentabilidade. Tal afirmação é confirmada mediante a análise do desempenho das notas nas questões relacionadas ao assunto, de tal modo foi possível identificar que inexiste uma linearidade entre as respostas (Frankenberger, Amarante, \& Vieira, 2017).

De Benedicto (2019), em sua dissertação de mestrado, analisou abordagem das Instituições de Ensino Superior em seus cursos de Administração sobre o tema gestão sustentável, com o fito de descrever sua contribuição no processo de ensinoaprendizagem de futuros administradores conscientes da importância de seu comprometimento com as práticas sustentáveis. Trata-se de uma pesquisa documental, na qual analisou-se os projetos pedagógicos de cursos de graduação em Administração no Estado de São Paulo. Os achados indicam pouca ênfase no tema sustentabilidade nas universidades que compuseram o estudo. Em que pese haver citação ao tema, observou-se que a sustentabilidade é identificada somente na bibliografia e na ementa da disciplina, não havendo indicativos da existência de um programa, afim de fomentar a temática de sustentabilidade. Outro aspecto relevante, é que as disciplinas, não costumam enfocar de forma consistente a sustentabilidade, e, por consequência, acabam não repassando a função do desenvolvimento social, econômico e ambiental, essenciais para a abordagem da sustentabilidade em sala de aula.

A partir da literatura consulta evidencia-se a valorização tanto pelos estudantes quanto pelos professores da temática na formação dos administradores. No entanto, também identificou-se dificuldades, dentre elas a abordagem que não alcança a interdisciplinaridade no Curso de Administração, além da pouca intenção dos docentes em se dedicar à área. Ainda, constatouse que a temática sustentabilidade ainda não está consolidada na graduação e que existem lacunas no entendimento dos estudantes referente a relação entre educação ambiental e sustentabilidade. Estas limitações convergem para a necessidade de ampliar as possibilidades que fomentem discussões acerca do tema, ao longo do curso de graduação em Administração, bem 
como a inserção no currículo de disciplinas que versem sobre educação ambiental e sustentabilidade, mesmo que de modo optativo, haja vista seu potencial de gerar reflexões, além de interações práticas, mediante o envolvimento dos estudantes em atividades que gerem benefício à sociedade e que promovam a preservação do meio ambiente e de estratégias que contribuam para a sustentabilidade.

Nem todos os Cursos de Administração possuem um componente curricular específico que abarca a educação ambiental. Alguns buscam propor atividades que envolvem o assunto e possibilitam a interação com outros cursos, transpondo a disciplinaridade em um caminhar para o alcance da transdisciplinariedade preconizada nas Diretrizes Curriculares Nacionais para Educação Ambiental. Deixando de ser, muitas vezes, uma disciplina isolada no curso, para se tornar uma proposta integrativa, coletiva e com maior potencial de transformação.

Além disso, outras estratégias podem ser implementadas, tais como: programas que envolvam a temática da educação ambiental, projetos de extensão, grupos e projetos pesquisa, bem como cenários que facilitem a participação dos estudantes e professores, com fulcro de socializar de modo transdisciplinar os conhecimentos, construir propostas coletivas que busquem promover mudanças tanto no cenário acadêmico, mas principalmente, expandir seu nível de abrangência à população, agregando valor social e beneficiando o maior número de pessoas com ações de cunho ambientalistas. Outra possibilidade é a abordagem transversal da educação ambiental, ou seja, ao longo do curso de Administração, para que possa ser discutida junto aos estudantes desde os semestres iniciais.

\section{Considerações Finais}

O estudo buscou fomentar reflexões sobre a inserção de temas ambientais e sustentáveis no Curso de Administração, focando no entendimento conceitual e na sua abordagem na perspectiva interdisciplinar e transdisciplinar.

Identificou-se a valorização da educação ambiental e da sustentabilidade pelos estudantes e professores durante a formação dos administradores. Todavia, percebemos que os estudos apontam fragilidades quanto à interdisciplinaridade e pouca intenção dos docentes em se dedicar aos temas socioambientais, contribuindo para que as temáticas ainda não estejam devidamente consolidadas na graduação; tendo sido identificadas lacunas no entendimento dos estudantes referente a relação entre educação ambiental e sustentabilidade.

No curso de Administração o assunto costuma estar presente, todavia ainda são necessários maiores investimentos e articulações para que transcenda apresentações pontuais em disciplinas isoladas, e passe a ocorrer de forma coletiva, interdisciplinar e transdisciplinar, aproveitando os diversos espaços de formação, como grupos e projetos de pesquisa e projetos de extensão.

O estudo corroborou para tecer reflexões acerca das estratégias de ensino e novas possibilidades que potencializam a abordagem da temática durante a graduação e lança a discussão a respeito do papel do administrador enquanto agente transformador e promotor de debates acerca das questões ambientais e suas repercussões no mundo empresarial, além da preocupação com bem estar social.

\section{Referências}

Brasil. (1999). Lei $n^{\circ}$ 9.795, de 27 de abril de 1999. Dispõe sobre a Educação. Ambiental, institui a Política da Educação Ambiental e dá outras providências. http://www.lei.adv.br/9795-99.htm.

Brasil. (2012). Resolução n. 2, de 15 de junho de 2012. Estabelece as Diretrizes Curriculares Nacionais para a Educação Ambiental. Diário Oficial da União, Brasília, n. 116, seção 1, p. 70, 18 jun. 2012. http://portal.mec.gov.br/dmdocuments/rcp002_12.pdf

Brasil.(2005). Programa Nacional de Educação Ambiental (ProNEA). (3a ed.),

Capponi, N. F., Ahlert, A., Dal'asta, D. \& Fiirst, C. (2021). Educação ambiental e Agenda 2030: percepção de gestores de uma rede de ensino básico e superior privado. Research, Society and Development, 10 (3), e3210312895. 
Research, Society and Development, v. 10, n. 9, e42610918163, 2021

(CC BY 4.0) | ISSN 2525-3409 | DOI: http://dx.doi.org/10.33448/rsd-v10i9.18163

Carvalho, M. M. S. \& Bispo, M. O. (2019). A educação ambiental sob a ótica da gestão nas instituições de ensino superior no fazer ambiental. Revista Terceiro Incluído, 9, 227-240.

De Benedicto, E. A. (2019). A sustentabilidade nos Cursos de Administração: uma reflexão sobre o ensino no Brasil. Campinas: PUC-Campinas. http://tede.bibliotecadigital.puc-campinas.edu.br:8080/jspui/bitstream/tede/1307/2/ELINE\%20ANY\%20DE\%20BENEDICTO.pdf.

Feil, A. A. \& Schreiber, D. (2017). Sustentabilidade e desenvolvimento sustentável: desvendando as sobreposições e alcances de seus significados. Cad. EBAPE, 14(3), 667-681

Frankenberger, F, Amarante, J.G.M.C. \& Vieira, A.M.D.P. (2017). Sustentabilidade no Curso de Administração: ensino é refletido no ENADE? Revista GUAL, 10(1), 171-188.

Jacobi, P. (1999). Poder local, políticas sociais e sustentabilidade. Saúde e Sociedade, 8(1),31-48.

Lopes, L. \& Morais, L.(2018). Temos um déficit de educação ambiental no Brasil. Educação Ambiental, Edição 112. https://espacoecologiconoar.com.br/temos-um-deficit-de-educacao-ambiental-no-brasil/.

Malta, S. O. M. \& Calloni, H. (2018). A Educação Ambiental no Ensino de Administração: desafios e perspectivas. Horizontes, 36(2), $102-113$.

Mikhailova, I. (2004). Sustentabilidade: evolução dos conceitos teóricos e os problemas da prática. Revista Economia e Desenvolvimento, 16, $22-41$.

Oliveira, L. G., Oliveira, D. M., Costa, F. J. (2010). A gestão ambiental nos Cursos de Administração: uma análise da perspectiva dos professores. Rev. Adm. UFSM, 3(2), 205-218.

Profice, C.C. (2016). Educação ambiental: dilemas e desafios no cenário acadêmico brasileiro. REDE Revista Eletrônica do PRODEMA, 10(1), $22-37$.

Roos, A, Becker, E. L. S. (2012). Educação ambiental e sustentabilidade. Revista Eletrônica em Gestão, Educação e Tecnologia Ambiental REGET/UFSM, $5(5), 857-866$.

Severino, A. J. (2007). Metodologia do trabalho científico. (23a ed.), Cortez.

Tauchen, J. \& Brandli, L. L. (2006). A gestão ambiental em instituições de ensino superior: modelo para implantação em campus universitário. Gestão \& Produção, 13(3), 503-515.

Teixeira, A. C. E. A. \& Teixeira, H. A. O ensino de administração e a educação ambiental: algumas reflexões sobre os currículos e a importância da formação de agentes multiplicadores nas organizações. Revista Gestão e Planejamento, 7(13), 14-21, 2006.

Teixeira, J. C. M, Queiros, A. P. C., Nogueira, C. M. S., Brito, M. L. A., Lima, E. R. M. \& Silva, A. M. A. (2018). O ensino de Gestão Ambiental na visão de discentes do curso de Administração. Revista Eletrônica Educação Ambiental em Ação, 1(38).

UNRIC. (2015). Centro Regional de Informação das Nações Unidas. Objetivos de desenvolvimento sustentável para transformar o mundo. https://www.unric.org/pt/17-objetivos-de-desenvolvimento-sustentavel. 